\title{
Dispersão Anemófila do Fungo Lasiodiplodia theobromae em Plantações de Coqueiro
}

\author{
Maiko S. Correia ${ }^{1 *}$ \& Jefferson L. da S. Costa ${ }^{2 *}$ \\ ${ }^{1}$ Universidade Federal de Sergipe, Departamento de Biologia; Avenida Marechal Rondon S/N, CEP 49001-000, \\ São Cristóvão, SE, e-mail: maiko@cpatc.embrapa.br; ${ }^{2}$ Embrapa Tabuleiros, Av. Beira Mar, no 3250, CEP 49025-040, \\ Aracaju, SE, e-mail: jcosta@cpatc.embrapa.br
}

(Aceito para publicação em 01/02/2005)

Autor para correspondência: Jefferson Luis da Silva Costa

CORREIA, M.S. \& COSTA, J.L.S. Dispersão anemófila do fungo Lasiodiplodia theobromae em plantações de coqueiro. Fitopatologia Brasileira 30:150-154. 2005.

\section{RESUMO}

Neste trabalho determinou-se a dispersão anemófila de conídios de Lasiodiplodia theobromae, agente causal da queima das folhas do coqueiro (Cocos nucifera), e sua relação com a precipitação pluviométrica. Para tanto, cinco armadilhas cata-vento e uma armadilha tipo Burkard, coletoras de esporos, foram instaladas nas entrelinhas de um coqueiral, a 1,80 m de altura do solo. Os conídios foram capturados em fitas transparentes, untadas com solução adesiva de gelvatol e vaselina. Semanalmente, as fitas foram retiradas das armadilhas e remontadas em lâminas para microscopia, onde era contado o número de conídios capturados, com auxilio de um microscópio. Esses dados foram coletados durante um ano e relacionados com dados pluviométricos obtidos na área experimental. Para as armadilhas cata-vento, a maior quantidade de conídios foi de 231 unidades, no mês de outubro. Para a armadilha Burkard, a maior quantidade capturada foi de 3.072 conídios, no mês de junho. Em geral, durante todo o ano, houve predominância na liberação de esporos no período diurno, ocorrendo maior captura entre 6:00 e 10:00 h. O número de conídios capturados pelos dois tipos de armadilhas relacionou-se com a precipitação de forma positiva entre 25 e $80 \mathrm{~mm}$, e após $80 \mathrm{~mm}$, negativamente. Foram estabelecidas curvas de tendências da quantidade de conídios capturados nos dois tipos de armadilhas, em função da pluviosidade mensal, através de equações de regressões cúbicas. As curvas apresentaram formatos semelhantes. A liberação dos conídios foi estimulada sempre que a pluviosidade mensal atingia o mínimo de $25 \mathrm{~mm}$. O ponto de máxima da curva, correspondente a $80 \mathrm{~mm}$ de chuva, indica que acima deste volume os conídios são precipitados do ar.

Palavras-chave adicionais: queima das folhas, aerobiologia, epidemiologia.

\begin{abstract}
Aerial dispersion of Lasiodiplodia theobromae in coconut plantations

The objective of this research was to study the aerial dispersion of Lasiodiplodia theobromae, the causal agent of coconut (Cocos nucifera) leaf blight, and its relationship with pluviometric precipitation. Five wind catcher spore traps and one Burkard spore trap were installed in a coconut plantation, at a height of $1.80 \mathrm{~m}$ from the ground. The conidia were captured in transparent tapes covered with gelvatol and vaseline. Every week, the tapes were retrieved and mounted on slides for microscopy, where the number of trapped conidia was determinated. For the wind catcher trap, the highest amount of trapped conidia was 231 units in the month of October. For the Burkard spore trap the highest amount of captured conidia was 3072 units achieved in June. In general, during a-year-round sampling, there was a predominance of conidia liberation during the diurnal period. The highest amount of conidia was captured from 6:00 to 10:00 a.m. The number of conidia trapped by the two types of devices correlated positively with the amount of precipitation ranging from 25 to $80 \mathrm{~mm}$. Above $80 \mathrm{~mm}$ of rain, the correlation was negative. Curves of tendency were established indicating that the amount of conidia captured by the two types of spore traps is a function of monthly precipitation and that both devices showed similar curves of tendency. The liberation of conidia was stimulated whenever precipitation reached a minimum of $25 \mathrm{~mm}$. The curves maximum point, correspond to $80 \mathrm{~mm}$ of rain, indicating that above this volume the conidia were precipitated.
\end{abstract}

Additional keywords: leaf blight, aerobiology, epidemiology.

\section{INTRODUÇÃO}

A cultura do coqueiro (Cocos nucifera L.) é de grande importância econômica para o Nordeste e está sujeita ao ataque de um grande número de doenças, dentre as quais se destaca a queima das folhas, causada pelo fungo Lasiodiplodia

\footnotetext{
*Bolsista do CNPq
}

theobromae Pat. (Ram, 1988). A doença está disseminada por todos os coqueirais fora da orla marítima e caracteriza-se principalmente pelo início da infecção no ápice foliar, que ao atingir a ráquis, progride internamente causando necrose e o enegrecimento dos tecidos foliares e provocando finalmente a morte prematura (Souza Filho et al., 1979; Warwick, 1990). Em conseqüência disto, os cachos perdem o apoio das folhas e os frutos caem antes de completar a maturação provocando 
queda na produtividade da cultura (Ram, 1989; Warwick, 1991).

Diante das elevadas perdas na produção geradas pela incidência dessa doença, surgiu o interesse no estudo de sua epidemiologia para permitir o desenvolvimento de medidas apropriadas de controle. Nesse tipo de estudo é conveniente a utilização de dispositivos coletores de esporos, os quais proporcionam informações complementares na avaliação indireta de doenças no campo. Esses dispositivos permitem determinar o comportamento da dispersão de propágulos fúngicos e quantificá-los. A quantificação é importante porque é possível fazer estudos de correlação com os fatores de clima. A captura de esporos a partir do uso desses dispositivos é dependente da sua produção, liberação, dispersão e deposição. Por outro lado, a dispersão é afetada pelas condições climáticas, principalmente pelo vento e pela chuva (Jenkin, 1971; Aita, 1983).

Além disso, o conhecimento epidemiológico das doenças permite a criação de modelos para previsão, que se bem desenvolvidos, fornecem a base para uma estratégia mais eficiente de controle (Fry, 1982; Sutton, 1988).

No Brasil, quantificações de esporos de alguns fungos fitopatogênicos capturados em armadilhas foram relatadas por diversos autores, em algumas culturas como o trigo (Triticum aestivum L.) (Santos et al., 1986), arroz (Oryza sativa L.) (Costa, 1991), jambeiro [Syzygium jambos (L.) Alston] (Blum \& Dianese, 2001) e milho (Zea mays L.) (Reis \& Mário, 2003).

Considerando a deficiência de informações epidemiológicas sobre a queima das folhas do coqueiro, realizou-se este trabalho com o objetivo de estudar a dispersão anemófila de conídios de $L$. theobromae, e o efeito da precipitação pluviométrica na quantidade de conídios no ar.

\section{MATERIAL E MÉTODOS}

Para realizar o monitoramento de conídios do fungo L. theobromae foram utilizadas uma armadilha coletora de esporos tipo Burkard (Burkard Scientific Instruments, Rickmansworth, Herts, U.K.) e cinco armadilhas do tipo catavento, conforme descrição de Reis \& Santos (1985). Estes dispositivos foram instalados nas entrelinhas de um coqueiral com os sintomas da queima das folhas no Município de Neópolis/SE, a 1,8 $\mathrm{m}$ do solo (correspondente à altura mediana da copa), onde permaneceram funcionando de junho de 2002 a maio de 2003 (Burkard) e de julho de 2002 a maio de 2003 (cata-vento).

A armadilha Burkard possuía uma bomba a vácuo que succionava o ar através de um orifício. A amostra de ar coletada era depositada em uma fita transparente do tipo Melinex, montada sobre um disco, que rotacionava no sentido horário com velocidade de $2 \mathrm{~mm} / \mathrm{h}$. A fita foi untada com uma camada de solução plástica gelvatol $10 \%$ dissolvida em água e uma outra camada de $90 \mathrm{~g}$ de vaselina com parafina dissolvida em tolueno. A fita era retirada do aparelho semanalmente, cortada em sete segmentos de $48 \mathrm{~mm}$, cada um dos quais correspondendo a um intervalo diário. Esses segmentos foram remontados em lâminas para microscopia untadas com uma solução de $35 \mathrm{~g}$ de gelvatol dissolvidos em $100 \mathrm{ml}$ de água $+50 \mathrm{~g}$ de glicerol $+2 \mathrm{~g}$ de fenol. Essas lâminas foram previamente marcadas com 24 espaços de $2 \mathrm{~mm}$, que representavam intervalos horários. O número de esporos coletados nesses espaços foi determinado em três pontos distintos para cada espaço, delimitado pelo campo visual do microscópio óptico com um aumento de 200 vezes.

Para as armadilhas cata-vento, utilizou-se como superfície de coleta de esporos a fita plástica Melinex, untada com a mesma solução adesiva usada para a armadilha Burkard. A fita foi montada em placas de Petri plásticas de 9 $\mathrm{cm}$ de diâmetro, as quais foram colocadas no interior das armadilhas, permanecendo expostas ao ambiente por uma semana. Após este período as fitas foram retiradas da placa de Petri de cada armadilha e remontadas sobre lâminas de microscopia conforme a metodologia descrita anteriormente. $\mathrm{O}$ número de esporos coletados por cada dispositivo foi determinado em dez pontos distintos para cada armadilha, delimitados pelo campo visual do microscópio óptico com um aumento de 200 vezes.

Os dados pluviométricos, para serem relacionados com a quantidade de conídios capturados pelos dois tipos de armadilhas de esporos, foram obtidos em uma estação meteorológica instalada no local do experimento.

Utilizou-se a análise de regressão para estabelecer modelos matemáticos de ajuste das curvas da quantidade de conídios, capturados pelas armadilhas Burkard e cata-vento, em função da pluviosidade mensal.

\section{RESULTADOS E DISCUSSÃO}

Neste trabalho, ambas as armadilhas utilizadas, tipo Burkard e tipo cata-vento, foram aptas a capturar conídios de L. theobromae durante todo o período de monitoramento (Figura 1).

A maior quantidade de conídios capturada pela armadilha Burkard ocorreu no mês de junho, totalizando 3072 unidades e nas armadilhas cata-vento ocorreu em outubro, totalizando 231 unidades (Figura 1).

De modo geral, a quantidade mensal de conídios capturados nos dois tipos de armadilhas relacionou-se de forma positiva com precipitações entre 25 e $80 \mathrm{~mm}$; acima deste valor a relação foi negativa. $O$ contraste entre a precipitação e o número de conídios capturados ajustou-se a uma curva de resposta polinomial. A liberação desses conídios foi estimulada sempre que a pluviosidade atingia valores superiores a $25 \mathrm{~mm}$. O ponto de máxima da curva foi correspondente a $80 \mathrm{~mm}$ de chuva; isto indica que acima deste valor os conídios começaram a ser precipitados do ar, e consequentemente resultam no decréscimo do número capturado (Figura 2).

Uma exceção ocorreu no mês de outubro, período em que foi constatada uma precipitação inferior a $20 \mathrm{~mm}$, no qual observou-se um pico aparentemente anormal de captura 
de conídios, quando comparado com os dados obtidos nos outros meses de monitoramento. Este evento pode ser atribuído a um aumento da umidade relativa do ar, que em setembro foi de $22,4 \%$ e em outubro subiu para $77,5 \%$, o que possivelmente elevou o fluxo aéreo de conídios, e, em conseqüência resultou em maiores coletas pelas armadilhas (Figura 1).

Além da determinação dos padrões de liberação e precipitação de esporos de L. theobromae, também foi constatado que, na maioria dos casos, o período de maior liberação dos esporos ocorreu durante o período diurno (Figura 3), compreendido entre os horários de 6 as $10 \mathrm{~h}$ (Figura 4).

Os resultados obtidos neste trabalho são concordantes com aqueles obtidos por vários autores, os quais observaram que em geral a liberação e precipitação de propágulos fúngicos anemófilos está diretamente relacionada com os índices de pluviosidade. Reis (1984) mostrou que a maior concentração de Helmintosporium sativum Pam. em trigo ocorreu somente após o período de estiagem; Hoy et al. (1991), utilizando armadilhas do tipo Kramer-Collins, que também funciona capturando esporos por sete dias consecutivos, constataram que houve um decréscimo de teliosporos de Ustilago scitaminea Sydow \& P. Sydow, após o aumento de chuvas; Blum \& Dianese (2001), utilizando uma armadilha Burkard, também detectaram um decréscimo na captura de urediniósporos após períodos de chuva. Por outro lado, Panisson et al. (2002) observaram que os propágulos de Gibberela zeae (Schw.) Petch em trigo eram coletados em maior número com a ocorrência de chuvas. Entretanto, o fenômeno de decréscimo dos propágulos nos períodos

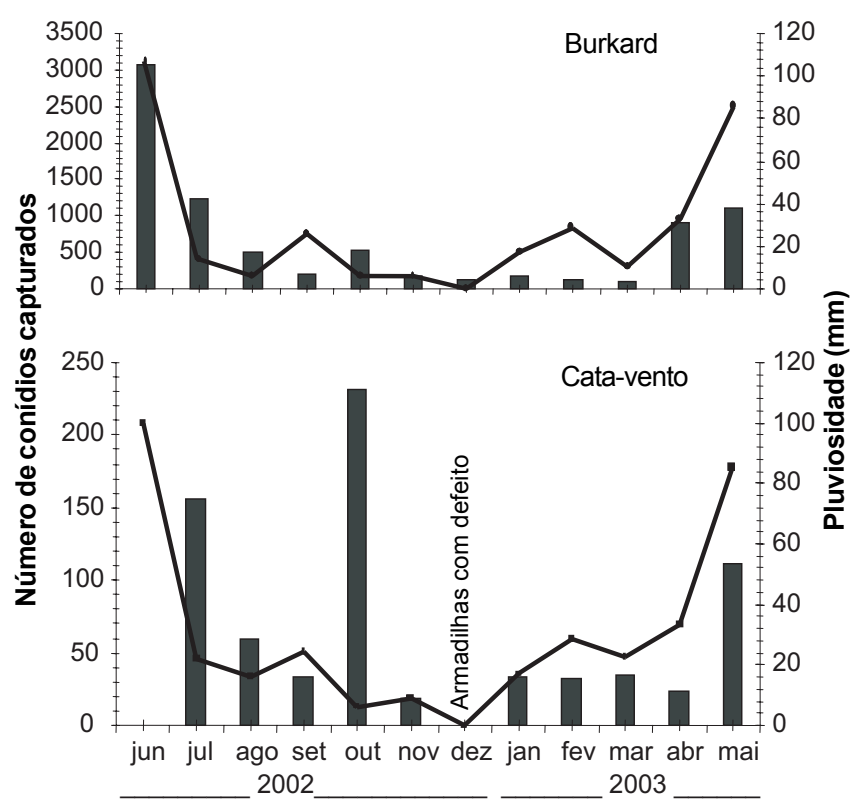

FIG. 1 - Total de pluviosidade mensal (linhas) e número de conídios de Lasiodiplodia theobromae capturados no campo (colunas) em armadilhas Burkard e cata-vento (Junho de 2002 a maio de 2003).

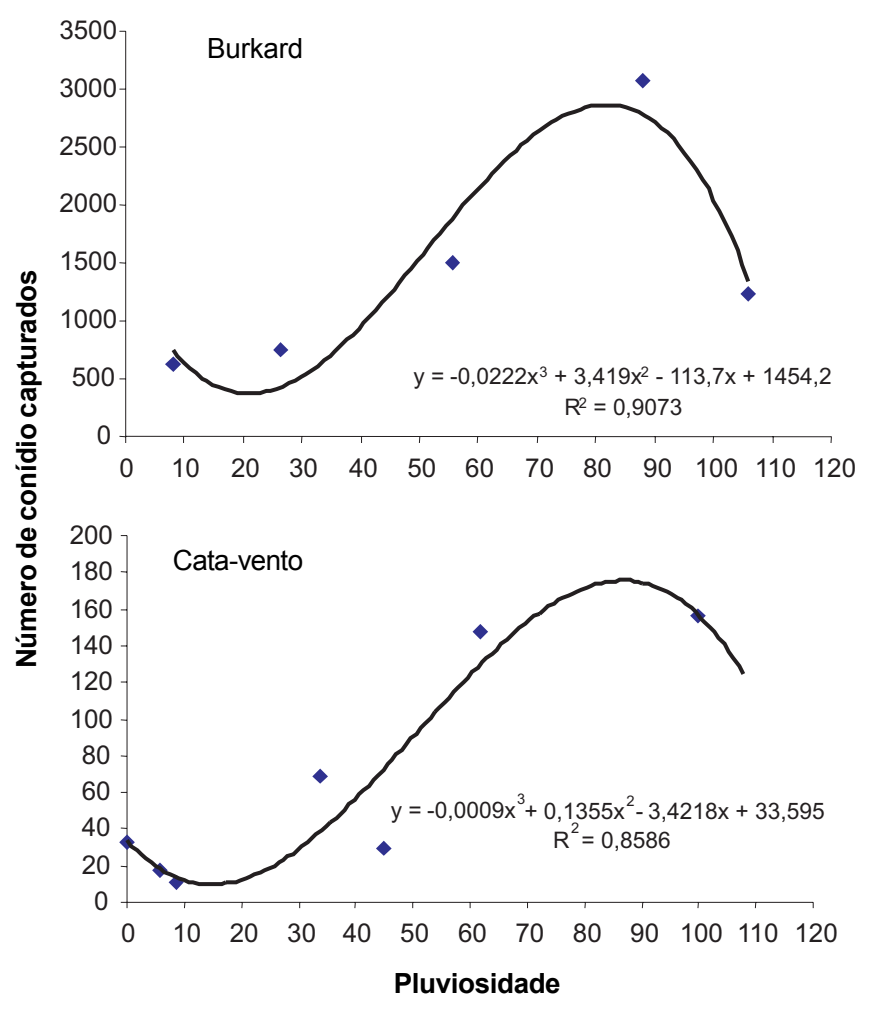

FIG. 2 - Influência da precipitação mensal na quantidade de esporos de Lasiodiplodia theobromae dispersos no ar, avaliada por armadilhas Burkard e cata-vento.

chuvosos também foi observado por estes autores.

A análise de regressão das quantidades de conídios capturados pelos dois tipos de armadilhas em função da pluviosidade permitiu a construção das curvas de tendências através de modelos cúbicos. Os formatos das curvas foram semelhantes, indicando que as variações observadas nas quantidades de conídios capturados foram bastante próximas (Figura 2). Apesar da semelhança entre os formatos das curvas, a armadilha Burkard demonstrou maior eficácia quanto à captura dos conídios (Figura 1). Isso pode ser atribuído à presença de uma bomba de sucção a vácuo nessa armadilha. As diferenças observadas entre os dados coletados nas armadilhas Burkard e cata-vento permitem concluir que os dispositivos distintos de coleta de esporos possuem desempenho diferenciado. Entretanto, a opção por uma armadilha do tipo cata-vento não irá interferir na decisão de qual estratégia será aplicada no controle de doenças de plantas, desde quando se deseja apenas detectar a presença de esporos no ar, em quantidade suficiente para iniciar um surto epidemiológico. Isto inclui a queima das folhas do coqueiro, pois, apesar da superioridade da Burkard na captura de conídios a curva de tendência da quantidade capturada é semelhante àquela gerada pelo tipo cata vento.

A relação entre a captura de esporos e a precipitação, obtida neste trabalho, merece uma comparação com os estudos de epidemiologia realizados por Ram (1989) e Warwick (1991). O primeiro autor, a partir da avaliação das folhas de 


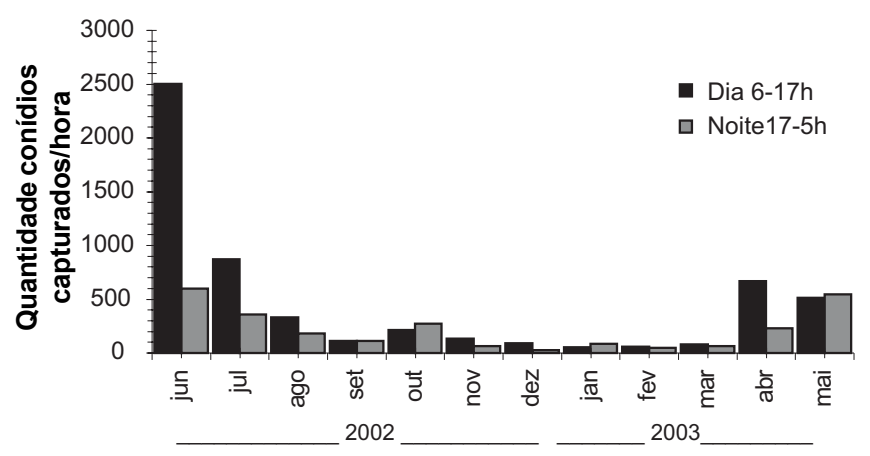

FIG. 3 - Quantidade de conídios de Lasiodiplodia theobromae capturados em armadilha Burkard em dois turnos diários, no período compreendido entre junho de 2002 e maio de 2003.

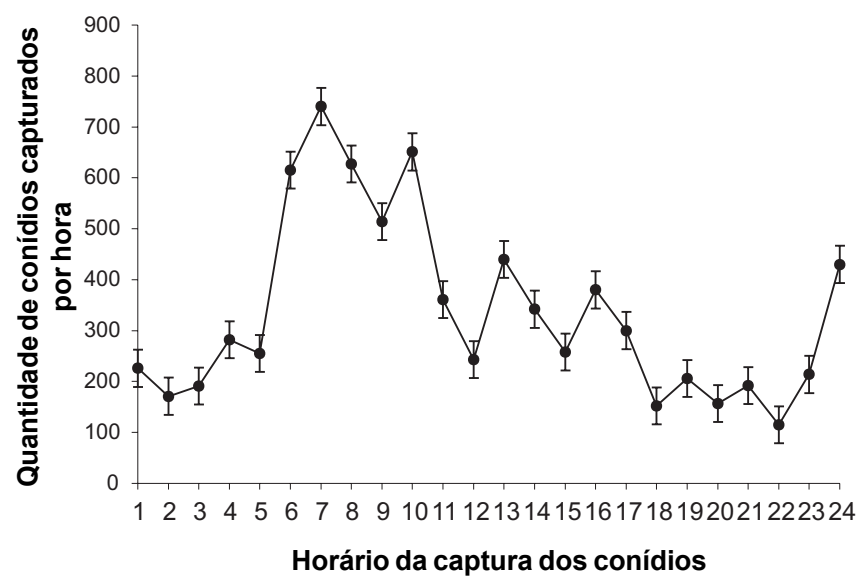

FIG. 4 - Número cumulativo total de conídios de lasodiplodia theobromae coletados pela armadilha Burkard em razão da hora do dia.

coqueiro doente constatou que a menor incidência da doença ocorreu no período em que a precipitação e a umidade relativa do ar eram altas; o segundo, em suas observações sobre a reação de coqueiros híbridos à queima das folhas também observou o mesmo fenômeno. A baixa incidência de doença observada pelos dois autores pode ser explicada pela lavagem dos esporos da atmosfera, no mês em que a precipitação acumulada foi superior a $80 \mathrm{~mm}$, como constatado no presente trabalho.

Portanto, chuvas de até $80 \mathrm{~mm}$ podem favorecer altos índices de infecção. O desenvolvimento e a conseqüente severidade da doença são dependentes de vários fatores, inclusive do estresse hídrico (estiagem). No estado de Sergipe, os novos plantios de coco são irrigados inadequadamente, havendo excesso do período de molhamento durante a época seca e isso, possivelmente, favorece o desenvolvimento da doença. É indiscutível a importância da chuva para início de surtos epidêmicos em determinados patossistemas. Na cultura do trigo, por exemplo, não se observou infecção de G. zeae em períodos sem precipitação (Reis 1988), além disso, a baixa precipitação pluvial foi responsável por uma baixa população desse fungo no campo (Panisson et al., 2002). Neste caso, possivelmente deve ter existido um sistema de irrigação adequado, que evitou o estresse hídrico, e, também a manifestação mais severa da doença na cultura.

Apesar deste trabalho não ter correlacionado a densidade de conídios no ar com os índices de infecção em folíolos durante o monitoramento, pôde-se determinar períodos de maior quantidade de inóculo no ar, mostrando a potencialidade de doença no campo e conhecer peculiaridades sobre a dispersão de esporos.

As informações deste trabalho poderão auxiliar na proposição de táticas de controle da queima das folhas do coqueiro, principalmente aquelas que incluam a aplicação de fungicidas.

\section{AGRADECIMENTOS}

Os autores agradecem ao $\mathrm{CNPq}$ pela concessão de auxílio bolsa durante o desenvolvimento do trabalho. À FINEP e à FAP- SE pelo auxílio financeiro. A Luciano Pinheiro, Carlos Eduardo Oliveira e Erivaldo Fonseca de Moraes pelo auxílio nos trabalhos realizados em campo.

\section{REFERENCIAS BIBLIOGRÁFICAS}

AITA, L. Informações sobre a coleta de alguns fungos fitopatogênicos por amostragem do ar. Fitopatologia Brasileira 8:377-379. 1983.

BLUM, L.E.B. \& DIANESE, L. Padrões de Liberação de urediniósporos e desenvolvimento da ferrugem em jambeiro. Pesquisa Agropecuária Brasileira 36:845-850. 2001.

COSTA, J.L. da S. Adaptação de uma armadilha para captura de propágulos fúngicos disseminados pela chuva. Summa Phytopatologica 17:276-280. 1991.

HOY, J. W., GRISHAM, M.P. \& CHAO, C.P. Production of sori and dispersal of teliospores of Ulstilago scitaminea in Lousiana. Phytopatology 81:574-579. 1991.

PANISSON, E., REIS, E.M. \& BOLLER, W. Quantificação de propágulos de Gibberela zeae no ar e infecção em anteras de trigo. Fitopatologia Brasileira 27:484-488. 2002.

RAM, C. Epidemiologia e controle químico da "Queima das folhas" (Lasiodiplodia theobromae) cocos nucifera. Fitopatologia Brasileira 14:215-220. 1989.

REIS, E.M. Quantificação de propágulos de Gibberela zeae no ar através de armadilhas de esporos. Fitopatologia Brasileira 13:324327. 1998.

REIS, E.M. \& MARIO, J.L. Quantificação do inóculo de Diplodia macrospora e de D. maydis em restos culturais, no ar, e sua relação com a infecção em grãos de milho. Fitopatologia brasileira 28:143147. 2003.

REIS, E.M. \& SANTOS. População de Helmintosporium sativum no ar quantificado através de uma armadilha do tipo cata-vento. Fitopatologia Brasileira 10:515-519. 1985.

SANTOS, J.R.N., DIANESE, J.C., ANJOS. J.R.N. \& NASSER. L.C.B. Aerobiologia de Puccinia graminis tritici e P. recondita no Distrito Federal. Fitopatologia Brasileira 11:581-586. 1986.

SOUZA FILHO, B.F., SANTOS, H.P. \& ROBBS, C.F. Etiologia da 


\section{M.S. Correia \& J.L.S. Costa}

queima das folhas do coqueiro. Fitopatologia Brasileira 1:5-10. 1979.

SUTTON, J.C. Predictive value of weather variables in the epidemiology and management on foliar diseases. Fitopatologia Brasileira 12. 305-311. 1998.

WARWICK, D.R.N., RIBEIRO, E.E. \& BEZERRA, AP.T.
Identificação de germoplasma do coqueiro-anão resistente à queima das folhas (Lasiodiplodia theobromae). Fitopatologia Brasileira 15:294-296.1990.

WARWICK, D.R.N., BEZERRA, A.P.O. \& RENARD, J.L. Reaciton of coconut hybrids to leaf blight (Lasiodiplodia theobromae Pat). Field observations. Oléagineux 46:100-108. 1991 